\title{
Effect of changes in heart rate on pressure half time in normally functioning mitral valve prostheses
}

\author{
JOHN CHAMBERS, NEIL MCLOUGHLIN, ANDREW RAPSON, \\ GRAHAM JACKSON \\ From the Cardiac Unit, King's College Hospital, London
}

SUMMARY To test the validity of a relation between the pressure half time and the diastolic times interval, previously shown in a pulse duplication system, eight patients with prosthetic mitra: valves and permanent pacemaker systems were studied. Recordings were made from the apex bj continuous wave or pulsed Doppler echocardiography at heart rates between 75 and 150 beats $/ \mathrm{min} . \dot{0}$ The pressure half time was found to be closely correlated with the diastolic time interval although there was individual variation and in three prostheses the pressure half time attained a plateau when the diastolic time interval was more than $300 \mathrm{~ms}$.

It is likely that the orifice area is the main controller of pressure half time where there is stenosig of the prosthesis, but that other factors such as ventricular or atrial compliance and the diastolie time interval may modify or obscure the effect of orifice area in normally functioning prosthetic valves.

The pressure half time is a measure of the rate of depressurisation of the left atrium and it is thought to be a comparatively flow independent indicator of orifice area in native mitral stenosis. ${ }^{1-3}$ There are, however, inconsistencies where pressure half time is considered in normally functioning mitral prostheses. The pressure half time correlates poorly with annulus diameter and may vary widely for one valve type between studies. ${ }^{45}$ There may be little difference in pressure half time in valves of widely different design. ${ }^{6} \mathrm{It}$ is therefore likely that where the area of the orifice is comparatively large, other factors such as ventricular or atrial compliance and diastolic filling time may have a disproportionate effect on pressure half time. ${ }^{78}$ Most studies, however, that have attempted to establish normal ranges for prosthetic function did not report information about flow or ventricular function. ${ }^{469}$

We showed in a pulse duplicator system with a regular cycle rate and stroke volume that pressure half time is independent of stroke volume but directly related to the diastolic time interval. ${ }^{7}$ In the present study we used patients with permanent pacemaker generators as a model with constant cycle length to test the effect of changing diastolic length on pressure half time.

Requests for reprints to Dr John Chambers, The Cardiac Unit, King's College Hospital, Denmark Hill, London SE5 9RS.

Accepted for publication 12 August 1988

\section{Patients and methods}

PATIENTS AND PROCEDURE

All nine patients on the King's College Hospitaहै database with both mitral prostheses and permanen implanted multiprogrammable pacemaker gener $\overrightarrow{0}$ ators were recruited. In one, differences in the timing of atrial activity made the shape of the Dopplee waveform too variable for analysis. The table shows. details of the remaining eight patients. All had VVE systems. No patient had symptoms or signs of either heart failure or prosthetic dysfunction although on (case 2) had a dilated, hypokinetic left ventricle on echocardiography. Imaging and Doppler echocar:diography showed normal cusp or occluder motion in all patients and no appreciable regurgitation.

The procedure was explained and the patient asked to lie semi-recumbent in the left lateral position. $1.9 \mathrm{MHz}$ continuous wave transducer was used. except in one patient with a bioprosthesis in whom pulsed Doppler with a duplex $2.5 \mathrm{MHz}$ transducer with the sample volume at the level of the stent tipso gave better signals. The probes were placed in the apical position and oriented with the forward flow by means of colour flow mapping. An assistant increase the pacemaker rate by 10 beats/min up to the highese programmable rate and then reduced it below the normally set rate until the patient's spontaneous. rhythm supervened. After a delay of 20 seconds at each increment at least 20 Doppler signals wered recorded onto thermal paper run at $100 \mathrm{~ms} / \mathrm{s}$. 
Table Demographic data in patients with permanent pacemaker generators and mitral prostheses

\begin{tabular}{lllll}
\hline Case & Valve type & Pacemaker type & LV function & Rhythm before pacing \\
\hline 1 & B-S & Telectronics Optima & Normal & CHB \\
2 & B-S & Telectronics Optima & Poor & Normal \\
3 & S-E & Telectronics Optima & Normal & Slow AF \\
4 & C-E & Telectronics Optima & Normal & Slow AF \\
5 & C-E & Biotronic Neos & Normal & Slow AF \\
6 & C-E & Cordis Stanicor Gamma & Sinus pauses \\
7 & S-E & Siemens 748T Dialog & Normal & CHB \\
8 & S-E & Telectronics Optima & & \\
\hline
\end{tabular}

AF, atrial fibrillation; B-S, Björk-Shiley; C-E, Carpentier-Edwards; CHB, complete heart block; LV, left ventricular; S-E, StarrEdwards.

DATA ANALYSIS AND STATISTICAL ANALYSIS Pressure half time was taken as the time for peak left ventricular inflow velocity to fall to $0.7 \times$ peak. $^{1}$ Many of the recordings had nonlinear deceleration slopes so we made measurements directly from the outline of the envelope rather than attempting to rule lines tangential to the waveform. Pressure half time was measured over 5-8 complexes at each cycle length and the mean and standard deviation were calculated. The diastolic time interval was measured from the start of the opening artefact to the midpoint of the closing artefact on each complex and the mean value was taken. Regression lines were drawn with standard commercially available computer software (Amstat1).

\section{Results}

RELATION BETWEEN DIASTOLIC INTERVAL AND CYCLE LENGTH

The diastolic time interval was directly related to cycle length $(r=0.97, y=0.80 x-222.64,95 \%$

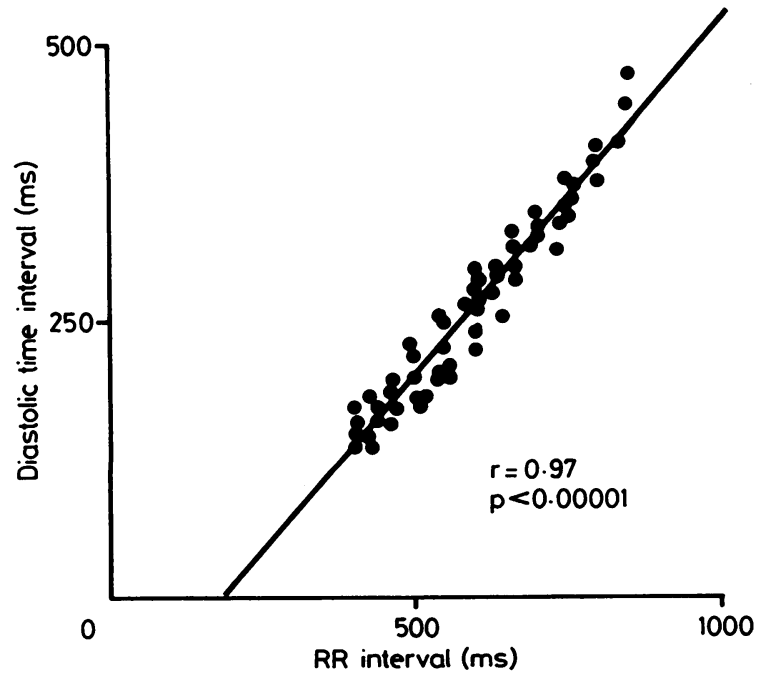

Fig 1 Diastolic time interval plotted against $R \boldsymbol{R}$ interval. The regression line is shown in bold. confidence interval for the slope 0.76 to 0.84 and for the intercept 188.75 to 256.53 ( $p<0.00001$ ) (fig 1 ).

\section{RELATION BETWEEN PRESSURE HALF TIME AND} DIASTOLIC TIME INTERVAL

Spectral recordings were generally satisfactory except in some patients at high rates when dense valve artefacts made measurement of pressure half time difficult. These traces were not measured. Examples of spectral recordings are given in fig 2 a and $b$. In patient 3 , the waveform had a fast deceleration phase and a subsequent slower phase which was seen only at lower heart rates. In the other patients, the basic configuration did not change but the waveform became wider at lower rates.

The pressure half time was directly related to the diastolic time interval $(r=0.81, y=8.77+0.28 x$, $95 \%$ confidence interval for intercept $-5 \cdot 71$ to $23 \cdot 25$ and slope 0.23 to $0.33, p<0.00001$ ) (fig 3 ). In most patients the relation between the pressure half time and the diastolic time interval was linear, although in two patients (cases 4 and 6) with a bioprosthesis and one with a Starr-Edwards prosthesis (case 7), it was curvilinear (fig 4). The slope of the relation was not dependent on valve type.

\section{Discussion}

In native mitral stenosis the pressure half time correlates well with the orifice area assessed by the Gorlin formula at simultaneous catheterisation. ${ }^{10}$ The same assumption underlies the universal use of pressure half time in the numerous studies attempting to define normal ranges for prosthetic mitral function. ${ }^{4-691112}$ Some $^{6}$ have even estimated orifice area from pressure half time by an empirical formula (220/ pressure half time) derived specifically for native stenosis that has never been validated adequately for prostheses. ${ }^{1}$ In fact, it has long been known from echocardiographic studies that the diastolic filling rate is dependent on left ventricular function as well as resistance to flow offered by the mitral valve. ${ }^{13}$ Thomas and Weyman ${ }^{8}$ have derived an expression 
(a) Patient 3

150

140

130

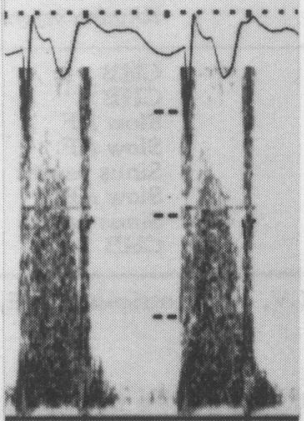

110
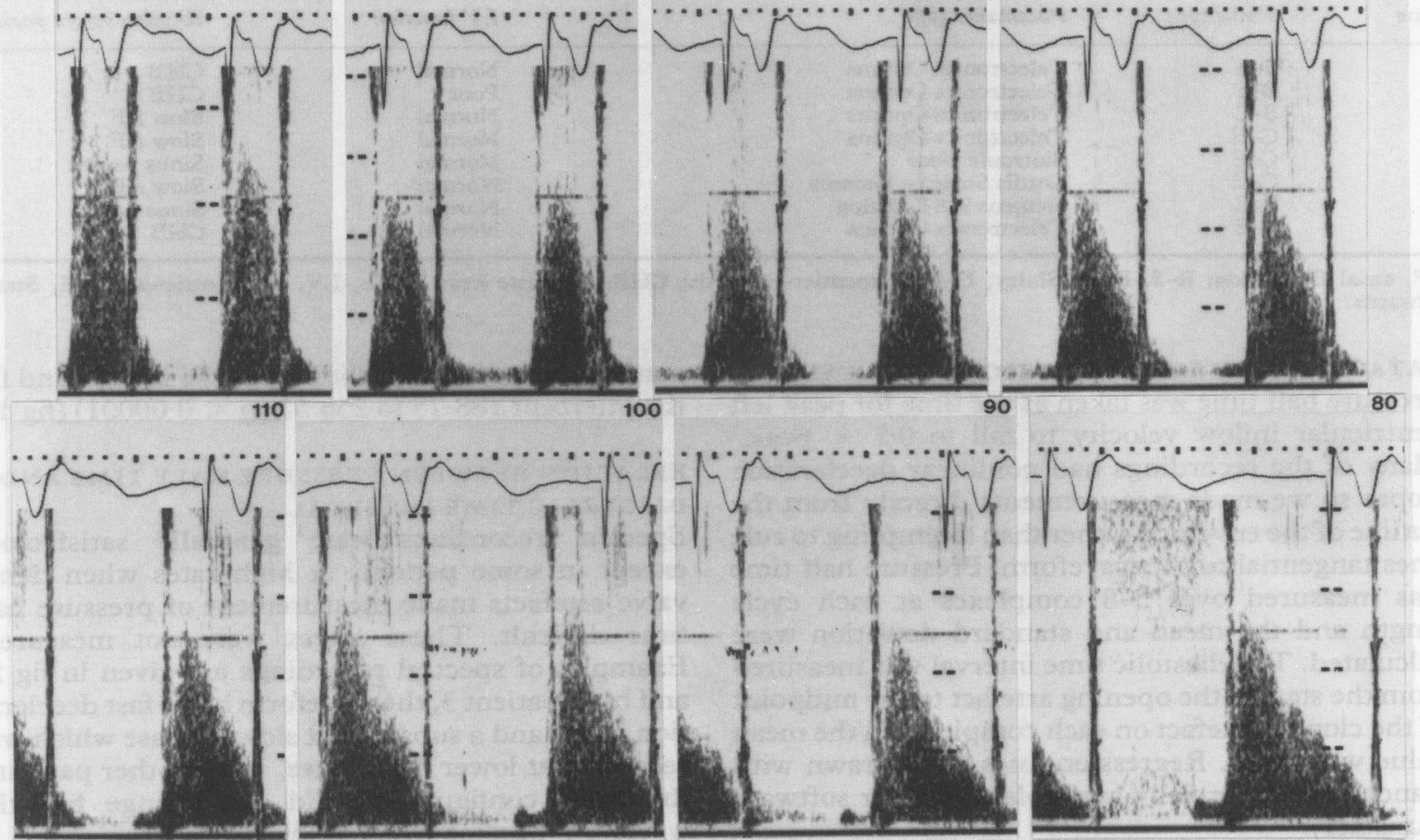

(b) Patient 4
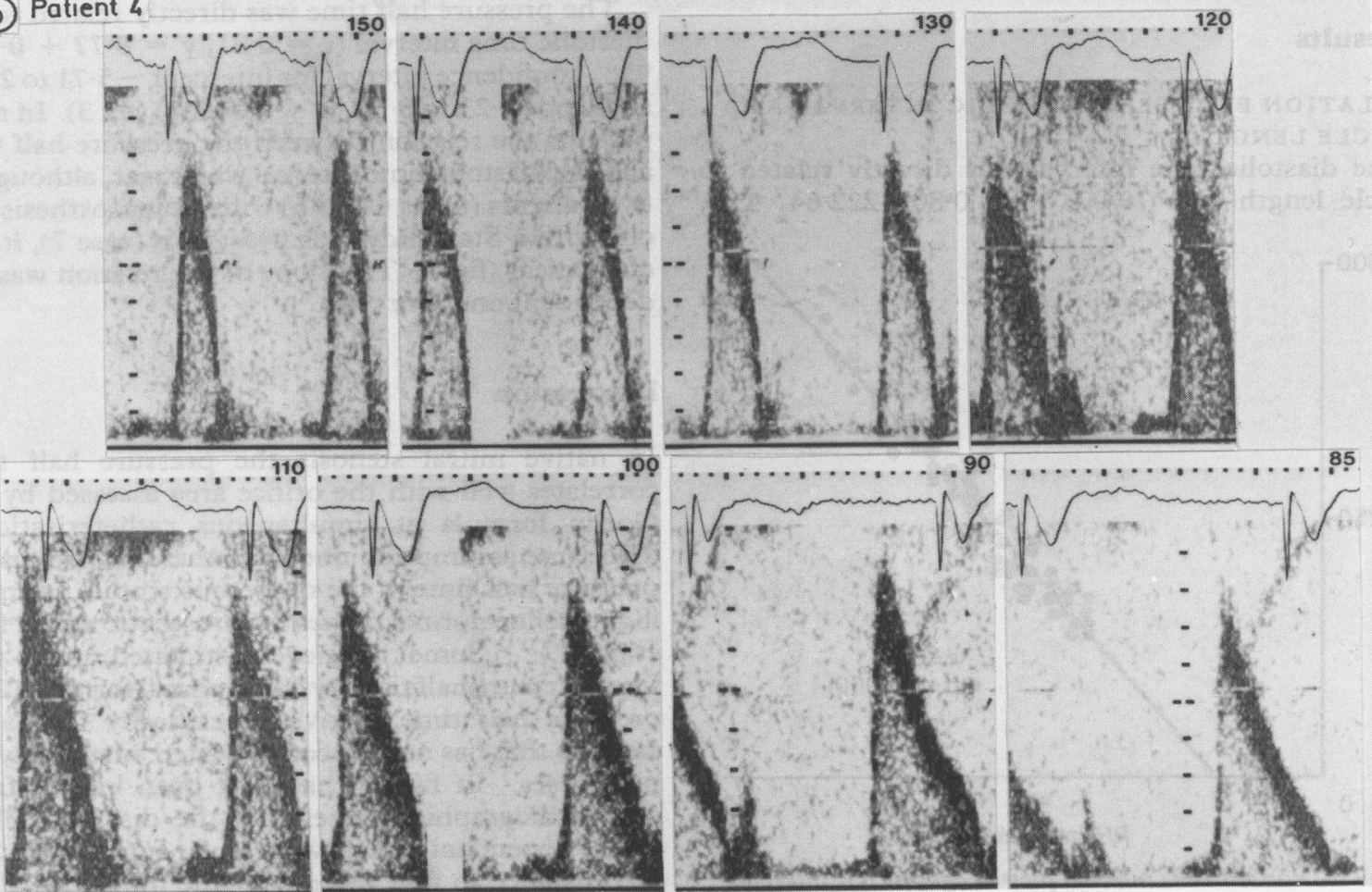

Fig 2 Two sets of left ventricular inflow recordings. (a) Continuous wave recordings from patient 3 who had a StarrEdwards prosthetis and (b) pulsed Doppler recordings from patient 4 who had a Carpentier-Edwards prosthesis. 


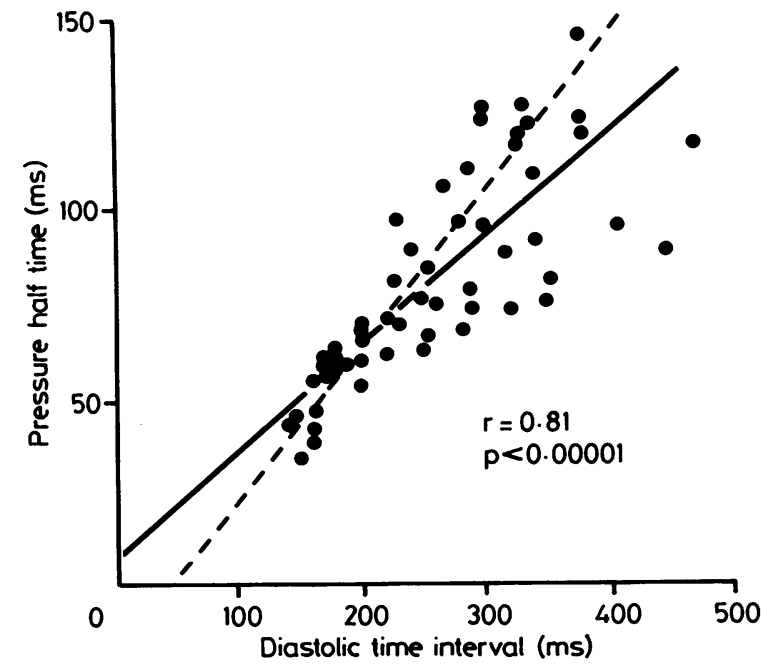

Fig 3 Pressure half-time plotted against diastolic time interval for all eight prostheses. The regression line from this pooled study is shown as a bold line. That from an experimental circuit is shown as a dotted line.

for pressure half time based on hydrodynamic theory which can be generalised to:

Pressure half time proportional to $(\mathrm{C} . \sqrt{ } \Delta \mathrm{p}) / \mathrm{MVA}$

$\mathrm{C}$ is combined atrial and ventricular compliance, $\Delta \mathrm{p}$ is the pressure difference between atrium and ventricle at the start of diastole, and MVA is mitral orifice
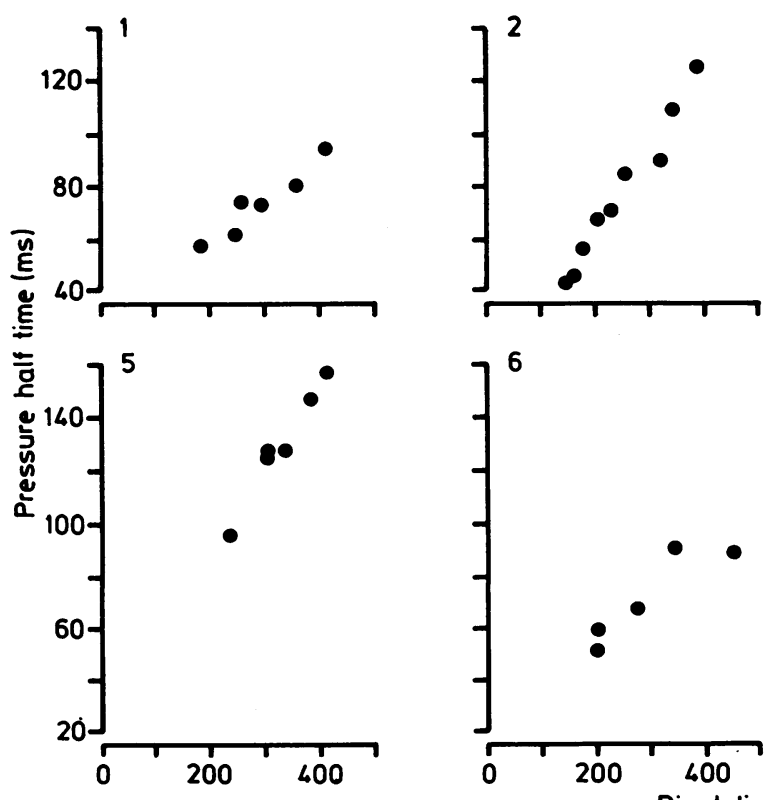

Diastolic time interval (ms)

Fig 4 Pressure half time plotted against diastolic time interval for prostheses in eight patients. area. These three factors are likely to interact to a degree that varies both with physiological and pathological state. The orifice area may be the main determinant of the pressure half time where there is a prosthetic stenosis, but in normally functioning prostheses its effect may be modified or obscured by the other factors. Thus Panidis et al found no difference in the pressure half time between normally functioning Starr-Edwards, Björk-Shiley, and biological prostheses in the mitral position ${ }^{6}$ although these valves have widely different behaviour in experimental circuits. ${ }^{15}$ The variability in the pressure half time between studies of one prosthesis may partly reflect statistical sampling or differences in technique, but it seems probable that differences in flow and ventricular function must also contribute. The mean pressure half time for CarpentierEdwards prostheses was $90 \mathrm{~ms}$ in a series of 38 reported by Gibbs et al, $128 \mathrm{~ms}$ in a series reported by Hatle and Angelsen, ${ }^{16}$ and $136 \mathrm{~ms}$ in 29 cases reported by Ryan et al ${ }^{4}$ (which however included some Hancock prostheses).

Similarly the effect of rate on atrial or ventricular compliance, atrial pressure, and orifice area is likely to vary with valve type and the presence of ventricular dysfunction. Thus although the relation between pressure half time and diastolic interval in this study was similar to that previously shown in an experimental circuit, ${ }^{7}$ there was increased scatter at comparatively long cycle lengths, and in some prostheses the pressure half time reached a plateau when
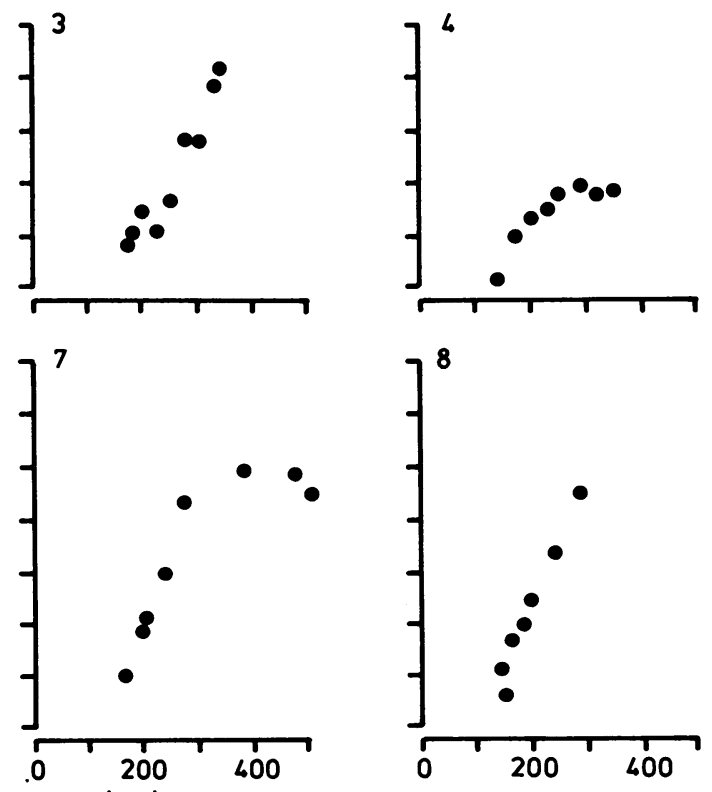
the diastolic interval was $>300 \mathrm{~ms}^{7}$ The relation was not tested at cycle rates below 75 beats $/ \mathrm{min}$. The effect of diastolic length may be different in a patient in atrial fibrillation rather than paced rhythm, although when Libanoff and Rodbard used cardiac catheterisation to study patients with mitral stenosis, the pressure half time varied from $110 \mathrm{~ms}$ to $170 \mathrm{~ms}$ over cycle lengths from $500 \mathrm{~ms}$ to $1000 \mathrm{~ms}^{3}$

Pressure half time may be less useful as a measure of orifice area in normally functioning prostheses than has previously been assumed. This is because it may be controlled partly by atrial or ventricular factors and varies with diastolic time interval. This study suggests that if the pressure half time of different valves is compared, cardiac cycles with a diastolic time interval of $\geqslant 300 \mathrm{~ms}$ should be chosen.

Dr J B Chambers holds a British Heart Foundation Junior Fellowship.

\section{References}

1 Hatle L, Angelsen B, Tromsdal A. Noninvasive assessment of atrioventricular pressure half-time by Doppler ultrasound. Circulation 1979;60:1096-104.

2 Libanoff AJ, Rodbard S. Evaluation of the severity of mitral stenosis and regurgitation. Circulation 1966; 33:218-26.

3 Libanoff AJ, Rodbard S. Atrioventricular half-time. Measure of mitral valve orifice area. Circulation 1968; 38:144-50.

4 Ryan T, Armstrong WF, Dillon JC, Feigenbaum H. Doppler echocardiographic evaluation of patients with porcine mitral valves. Am Heart $J$ 1986;111: 237-44.

5 Gibbs JL, Wharton GA, Williams GJ. Doppler echocardiographic characteristics of the CarpentierEdwards xenograft. Eur Heart J 1986;7:353-6.

6 Panidis IP, Ross J, Mintz GS. Normal and abnormal prosthetic valve function as assessed by Doppler.: echocardiography. J Am Coll Cardiol 1986;8:317-26.

7 Chambers JB, Cochrane T, Black MM, Jackson G. $\stackrel{\text { ? }}{+}$ In vitro validation of the assessment by Doppler? ultrasound of normal mitral bioprosthetic function [Abstract]. J Am Coll Cardiol 1988;11:22A.

8 Thomas JD, Weyman AE. Doppler mitral pressure half-time: a clinical tool in search of theoretical justification. J Am Coll Cardiol 1987;10:923-9.

9 Simpson IA, Reece IJ, Houston AB, Hutton I, $\overrightarrow{0}$ Wheatley DJ, Cobbe SM. Non-invasive assessment by Doppler ultrasound of 155 patients with biopros- $\vec{\omega}$ thetic valves: a comparison of the Wessex porcine, low profile Ionescu-Shiley, and Hancock pericardial bioprostheses. Br Heart J 1986;56:83-8.

10 Nakatani S, Masuyama T, Kodama K, Kitabatake $A_{j}$ Fujii K, Kamada T. Value and limitations of Doppleri echocardiography in the quantification of stenotio mitral valve area: comparison of the pressureo half-time and the continuity equation methods. Circulation 1988;77:78-85.

11 Weinstein IR, Marbarger JP, Perez JE. Ultrasonic assessment of the St Jude prosthetic valve: $\mathbf{M}$ mode, two-dimensional, and Doppler echocardiography. Circulation 1983;68:897-905.

12 Sagar KB, Wann S, Paulsen WHJ, Romhilt DW. Doppler echocardiographic evaluation of Hancocko and Björk-Shiley prosthetic valves. J Am Coll Cardio ${ }^{\circ}$ 1986;7:681-7.

13 Dawkins KD, Cotter L, Gibson DG. Assessment of mitral Björk-Shiley prosthetic dysfunction using digitised $\mathrm{M}$ mode echocardiography. $\mathrm{Br}$ Heart 1984;51:168-74.

14 Brodie BR, Grossman W, McLaurin L, Starek PJK, Craige E. Diagnosis of prosthetic mitral valve mal function with combined echo-phonocardiography Circulation 1976;53:93-100.

15 Fisher J, Reece IJ, Wheatley DJ. In vitro evaluation of six mechanical and six bioprosthetic valves. Thoras Cardiovasc Surg 1986;34:157-62.

16 Hatle L, Angelsen B. Doppler ultrasound in cardiology Philadelphia: Lea and Febiger, 1985:196. 